\title{
The Research on the Changes of International Energy Structure and China's Coping Strategies against the Background of Global Energy Interconnection
}

\author{
Ming Zeng ${ }^{1}$, Weicheng Chen ${ }^{1,} a,{ }^{*}$, Xiaoxuan Wang ${ }^{1}$, Pengcheng Zhou ${ }^{1}$, \\ Chenjun Sun ${ }^{2}$ \\ ${ }^{1}$ State Key Laboratory for Alternate Electrical Power System with Renewable Energy Sources, North \\ China Electric Power University, Beijing, China; \\ ${ }^{2}$ State Grid Hebei Electric Power Company, Hebei, China. \\ *eversf@126.com
}

Keywords: Global energy interconnection; international energy structure; Chinese energy supply structure.

\begin{abstract}
With the rise of the emerging countries and the changes in the international economic pattern, the development of new energy resources and the progress of energy saving technology, all countries of the world have begun to develop renewable clean energy, and the global energy interconnection came into being. In this context, this paper firstly analyzes the changes of the international energy structure under the global energy interconnection construction from the two aspects of the international energy consumption pattern and the international energy development pattern. Secondly, from the two aspects of Chinese energy supply structure and energy security, this paper studies the impact of changes in the international energy structure on Chinese energy development. Finally, based on the changes in the international energy structure and its impact on Chinese energy development, this paper puts forward some strategies and suggestions for Chinese response to the global energy interconnection construction and the changes in the international energy structure.
\end{abstract}

\section{Introduction}

For a long time, the development of global energy is overly dependent on fossil fuels, which has led to more and more serious problems, such as resource tension, climate change, environmental pollution and so on, which seriously threaten the survival and development of human beings[1]. With the rise of the emerging countries and the change of the international economic pattern, the development of new energy resources and the progress of energy saving technology, all countries of the world have begun to develop renewable clean energy [2], such as hydropower, wind energy and solar energy, and pay attention to the interconnection of global energy, and the global energy interconnection arises at the historic moment. The global energy interconnection is a globally connected strong and smart grid that is based on the smart grid, with UHV grid as the backbone network, the transport of clean energy as the leading[3]. In the context of the current global energy interconnection, the international energy demand pattern and development pattern will vary in varying degrees. These changes will have a significant impact on Chinese energy structure. China needs to adopt a series of coping strategies to cope with these effects. In view of these, this paper firstly analyzes the trend of international energy consumption pattern and development pattern under the global energy interconnection background. Secondly, from the two aspects of Chinese energy supply structure and energy security, this paper studies the impact of changes in the international energy structure on Chinese energy development. Finally, this paper puts forward pertinent strategies for China to tackle the global energy interconnection construction and changes in the international energy structure. 


\section{Analysis of Changes in the International Energy Structure Under the Global Energy Interconnection Construction}

Under the background of global energy interconnection, the degree of international energy interconnection is constantly improving, and the international energy structure is constantly changing, including the changes of consumption pattern and development pattern.

\subsection{Changes in International Energy Consumption Structure.}

At present, developed countries are in the leading position in the structure of energy consumption. This is manifested not only in the fact that the total energy consumption and per capita consumption in developed countries are far higher than those in developing countries, but also in the fact that developed countries have strong voice, rulemaking and financial manipulation rights in the global energy consumption market[4].

However, the comparison of energy consumption between developed and developing countries is undergoing significant changes. On the one hand, because the economic growth of major developed countries in the world is relatively slow, the growth of energy consumption is relatively small. On the other hand, developing countries, especially emerging powers, are experiencing rapid economic development and sustained growth in their energy consumption. The energy consumption of developed and developing countries varies from two directions, and the total energy consumption of developing countries may gradually surpass that of developed countries.

With the steady growth of the global economy and population and the improvement of energy efficiency, it is estimated that in 2050, the total global GDP will reach around 220 trillion dollars, and the total global primary energy demand will increase to 30 billion tons of standard coal. At the same time, the elasticity coefficient of energy consumption will decline steadily in the future, supporting faster economic growth with lower energy growth rate. It is estimated that by 2050, the proportion of fossil fuels consumption will decrease from $86.7 \%$ in 2013 to $22 \%$, while the proportion of non-fossil fuels consumption will increase from $13.3 \%$ in 2013 to $78 \%$, for specific data, which is shown in figure 1 . In general, in the future, the international energy consumption pattern will realize the fundamental transformation from the main of fossil fuels, supplemented by clean energy, to the main of clean energy and supplemented by fossil fuels.

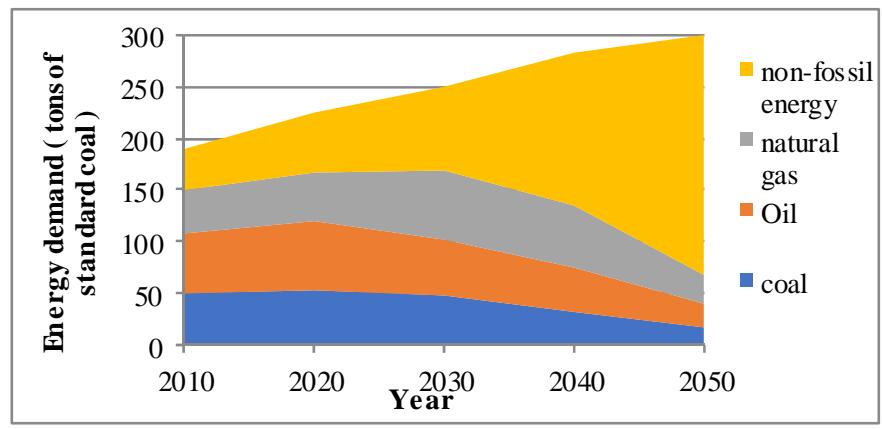

Figure 1. Global primary energy demand by varieties from 2010 to 2050

\subsection{Changes in International Energy Development Structure.}

From the perspective of energy demand, the world's primary energy demand will reach 300 billion tons of standard coal in 2050, of which electricity demand will reach 73 trillion kilowatt hours. To meet the needs of such a large scale of energy and electricity, the structure of international energy development will undergo significant changes [5]. Especially in the low carbon development environment of climate change, the replacement of clean energy is accelerated, the scale of renewable energy development and utilization is greatly increased, the proportion of the energy development structure is increasing, and the fossil fuels will be gradually replaced by the fossil fuels as the leading energy in the future.

The current structure of international energy development is still the main source of fossil fuels development in the Middle East Bay, North America, Latin America and the rapid development of the annulus and the oil and gas producing areas of Africa in recent years. But in the future, clean energy development will become the leading energy for future development. 
The Middle East Gulf has the most abundant oil and gas resources, and has been the main source of oil and gas in the world for decades. North America has always been an important oil and gas production center in the world. With the advance of shale oil and gas resources exploration and development in the United States, the United States is expected to become the world's largest oil and gas producer by 2020. With the global warming, the development of oil and gas in the Arctic area is constantly expanding, and the development potential of Canadian oil sands is enormous. The future position of North America in the world oil and gas production structure is expected to increase significantly, and it may become the world's major oil and gas producing area after the Middle East Gulf.

Before 2030, the better hydropower resources will be developed, and all kinds of non-water renewable energy will continue to develop rapidly. The 2/3 of the global new development energy comes from renewable energy, and more than $50 \%$ of the new demand is met by renewable energy, such as wind energy and solar energy. Nevertheless, by 2030, the supply of fossil fuels such as coal, oil and natural gas still accounts for about 2/3 of the primary energy demand. After 2030, the technologies for the development and utilization of renewable energy, such as wind and solar energy, will be more mature, the conversion efficiency and economy will continue to rise, and the replacement of traditional fossil fuels, especially coal and oil, will increase the development of coal, oil and natural gas, and the new energy resources demand is supplied by renewable energy. .

As the leading energy in the future, the development of clean energy will form a new structure of international energy development, which is based on base type and distributed as a supplement. The development of renewable energy bases such as hydro energy, wind energy and solar energy will accelerate in the Arctic, equator, and continents. Specifically, it is estimated that by 2050, the global clean energy generation will reach 6 billion 600 million $\mathrm{kWh}$, accounting for $90 \%$ of the total electricity consumption. The solar and wind energy generation will account for $66 \%$ of the total electricity, $14 \%$ of the total electricity, $10 \%$ of the biomass and other total electricity, and about $10 \%$ of the total electricity and nuclear power. From the development of clean energy in various continents, by 2050, the energy of clean energy in Asia is about $49 \%$ of the total energy of clean energy in the world; Africa accounts for about $16 \%$ of the total energy of clean energy in the world, and it becomes the most important solar energy development zone. In 2050, the global power supply structure is shown in Figure 2. In 2050, the amount of clean energy generated in all continents is shown in Figure 3.

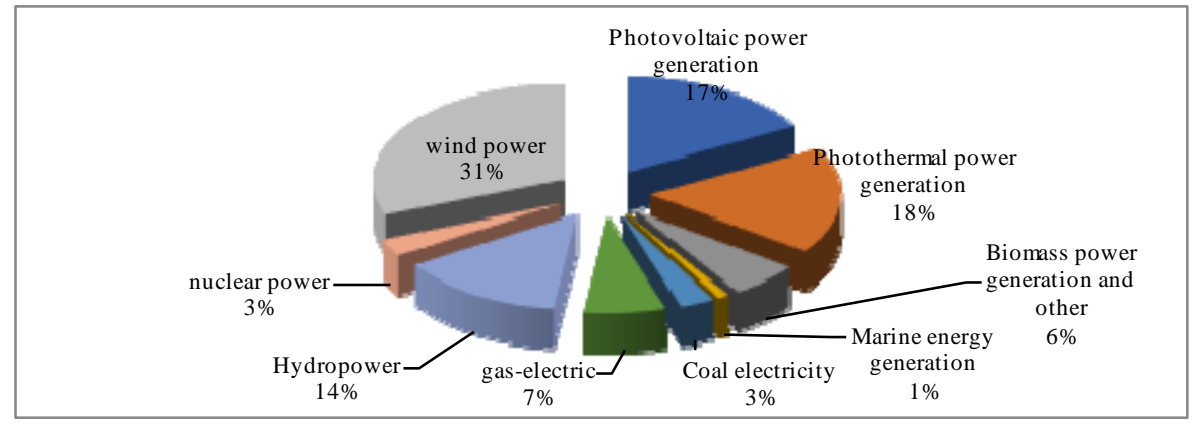

Figure 2. Global power supply structure in 2050

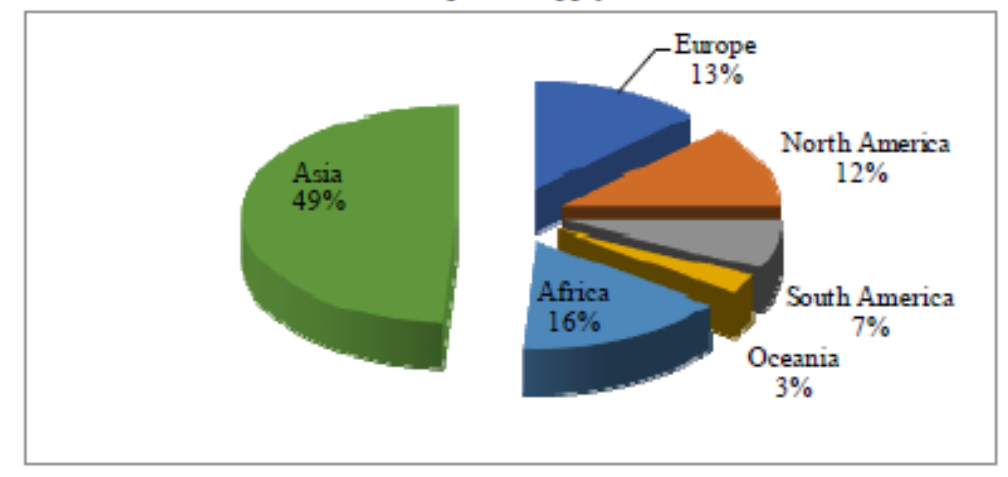

Figure 3. Percentage of clean energy generating capacity in 2050 on all continents 


\section{Research on the Impact of Changes in the International Energy Structure on Chinese Energy Development}

China is a stakeholder in the changing world energy structure. China is not only a big energy consuming country in the world, but also a big energy producing country in the world. The new changes in the world's energy structure must have a far-reaching impact on Chinese energy security. 3.1 Research on the Impact of Changes in the International Energy Structure on Chinese Energy Supply Structure.

China has become the largest energy consumer and producer in the world. The total energy consumption in 2016 was 43.6 million tons of standard coal, which increased by 60 million tons of standard coal, increased by $1.4 \%$, and the total energy consumption accounted for $23 \%$ of the global energy consumption. Among them, the proportion of coal, oil, natural gas, primary electricity and other energy accounts for $62 \%$ of total energy consumption, $18.3 \%, 6.4 \%$ and $13.3 \%$ respectively. In 2016, Chinese total energy production amounted to 34.6 billion tons of standard coal, and energy production accounted for $79 \%$ of energy consumption. Among them, the proportion of raw coal, crude oil, natural gas, primary electricity and other energy accounts for $69.6 \%$ of total energy production, $8.2 \%, 5.3 \%$ and $16.9 \%$ respectively.

Although the total amount of energy production in China ranks first in the world, the endowment of energy resources is not high, the per capita possession of conventional oil and natural gas resources is low, and the contradiction of energy resource constraints is prominent. Chinese high energy consumption industry accounts for a large proportion, and its energy utilization and development methods are backward. The energy consumption per unit GDP is much higher than that of the developed countries. The overall recovery rate of coal resources is only $30 \%$, and the comprehensive efficiency of energy processing, transformation, storage and transportation and terminal utilization is only $36 \%$. In 2017, Chinese crude oil dependence rate has exceeded 65\%. Not only oil, natural gas, uranium resources, but also coal in less than 10 years, from a big net exporter to the largest net importer. China has been the fastest growing energy market in the world for sixteenth years in a row.

In the future, the international energy consumption structure and development structure will realize the fundamental transformation from fossil fuels to clean energy and to clean energy and fossil fuels. As the largest energy consumer and producer in the world, the changes in the international energy structure will have a significant impact on the energy supply structure in China. The impact of Chinese energy supply structure is as follows:

(1) Fossil fuels consumption has been declining and non-fossil fuels consumption has increased significantly. The major impact of changes in the international energy structure on Chinese energy structure is that the proportion of fossil fuel consumption has been decreasing and the proportion of non-fossil fuels consumption has increased significantly. From the data of China Statistical Yearbook, Chinese coal consumption has declined for three years in 2014 2016. In 2016, coal consumption declined by 1.85 million tons of standard coal in 2015, down by $4.7 \%$. It is estimated that by 2050 , Chinese coal consumption will account for less than $50 \%$ of total energy consumption. In 2016, Chinese non-fossil fuels consumption increased by nearly 60 million tons of standard coal over the same period last year, contributing to the increment of energy consumption.

(2) Electricity consumption growth is stable, and the third industry and residential electricity consumption have increased considerably. In the context of the global energy interconnection, the impact of the international energy structure on Chinese electricity consumption is mainly due to the continuous increase of Chinese electricity consumption. Chinese total electricity consumption in 2016 was 5 trillion and 920 billion kWh, an increase of 282 billion 500 million kWh compared with the same period last year, an increase of $5 \%$, and the steady growth of electricity consumption.

(3) The production of fossil fuels has decreased significantly, and the supply of clean energy has increased significantly. The international energy development structure will lead to the development of clean energy, which will also affect the structure of Chinese energy development, reduce the supply of fossil fuels and enhance the supply of clean energy. In 2016, the total output of primary energy in China was about 34.6 billion tons of standard coal, down $4.2 \%$ from the same period last 
year. In 2016, the production of coal fell sharply, the output of raw coal was 34.1 million tons, 3.4 million tons, down 9\%, which was the same as the declining trend of coal consumption in the past three years. In 2016, Chinese energy output was negatively increased by 154 million 760 thousand tons of standard coal, and the output of coal declined substantially, but the output of clean energy increased by about 60 million tons of standard coal. It is estimated that by 2030, Chinese total generating capacity will reach 10 trillion $\mathrm{kWh}$, and clean energy will account for more than half of the total electricity generation.

\subsection{Research on the Impact of Changes in the International Energy Structure on Chinese Energy Security.}

At present, China is in a critical period of accelerated development of industrialization, urbanization and modernization. It is difficult to adjust the energy structure with high energy consumption, and the trend of large energy demand growth is difficult to reverse in a short time. It is estimated that by 2020, Chinese external dependence on energy may exceed $30 \%$, of which the dependence on foreign oil may exceed $70 \%$.

The rapid growth of energy consumption in China and the slow growth of energy supply in the world constitute a structural contradiction, which will inevitably increase the difficulty and cost of Chinese access to foreign energy resources, and lead to contradictions and conflicts between China and other countries. In addition, some countries have spread the "China Energy Threat Theory", although the remarks are exaggerated and they have ulterior motives, if China cannot effectively adjust the energy consumption structure, it is likely to fall into a great strategic passivity in the face of such attacks.

As the United States gradually realizes the "energy independence", its dependence on the oil and gas supply in the Middle East Bay will fall sharply. This will lower the US demand for maintaining the safety of the sea route, thus reducing the military input in the strategic key of the channel. As Chinese energy demand continues to grow, the current situation of over $50 \%$ of oil and gas imports from the Middle East and North Africa is difficult to fundamentally change. In order to meet the energy needs of oil and gas, China needs to make greater efforts to maintain the stability of the situation in the region, bear greater responsibility and face a more intense game of great powers.

\section{Strategies and Suggestions for Chinese Response to the Global Energy Interconnection Construction and the Changes in the International Energy Structure}

Under the background of current energy interconnection construction, China, as an energy power, needs to take a series of actions if it wants to play a leading and positive role in the changing tide of international energy structure. Specifically, China should actively develop clean energy and increase the development of solar energy, wind energy, hydropower, nuclear energy and biomass energy. China should strengthen Chinese international energy cooperation [6].

\subsection{Actively Develop Clean Energy.}

As the leading energy in the future, Chinese clean development and utilization is still in the preliminary stage, and its technology and economic potential are huge. The main clean energy development in China includes solar energy, wind energy, hydropower, nuclear energy and biomass energy.

\subsubsection{The Development of Solar Energy.}

(1) To promote the construction of large photovoltaic power station in an orderly way. In the central and western regions with good resource conditions, access to power grids and strong absorptive capacity, the photovoltaic power station construction will be promoted in an orderly way on the premise of effectively solving the existing problem of light rejection. Actively support the application of advanced photovoltaic technologies and products in the central and eastern regions, combining with the requirements of environmental governance and land reuse, and accelerate the survival of the fittest in the market and the rapid decline of photovoltaic grid tariff. In areas rich in hydropower resources, water-light complementation or joint delivery demonstration can be carried out by utilizing hydropower regulation capacity. 
(2) Promote the distributed photovoltaic comprehensively and "photovoltaic + " comprehensive utilization project. Promote the large-scale promotion of roof photovoltaic power generation system in industrial parks vigorously, economic development zones and other concentrated areas. Actively encourage the construction of photovoltaic power station projects in accordance with the principle of nearby utilization in central and eastern cities and industrial areas where the power load is large and the industrial and commercial basis is good; Combining the comprehensive utilization of land, relying on agricultural cultivation, fishery cultivation and forestry cultivation, we will innovate various commercial modes of "photovoltaic+" comprehensive utilization according to local conditions, and promote the organic integration of photovoltaic and other industries.

(3) Promote the diversified development of solar energy heat utilization vigorously. We will continue to expand the popularization and application of solar energy heat utilization in urban and rural areas, actively promote the development of solar energy heating and refrigeration technology, realize the large-scale utilization of solar energy hot water, heating and refrigeration systems, and promote the complementary application of solar energy and other energy sources.

\subsubsection{The Exploit of Wind Energy.}

(1) Orderly construction of the Three North Areas of China large wind energy bases. On the basis of fully excavating the local wind power dissipation capacity, with the help of the UHV Trans province transmission channel in the Three North Areas of China, the wind, light, water, fire and other kinds of power are coordinated to promote wind power consumption. Combined with the changing trend of power supply and demand, the development and efficient utilization of wind power in the Three North Areas of China should be promoted.

(2) Intensifying the construction of decentralized wind energy. We should strengthen the exploration of wind energy resources in the Middle East and southern regions, improve the technology and micro location of the low wind speed wind turbines, and comprehensively promote the development and utilization of wind energy resources in the Middle East and southern regions. Combining the layout of the power grid and the upgrading and upgrading of the rural power grid, the technical standard and the grid service system of the distributed wind energy are perfected, and the construction conditions such as resources, land, transportation and construction and installation are considered, and the construction of distributed wind energy is promoted.

(3) Promote the development of wind energy at sea actively and steadily. We will carry out the survey and evaluation of offshore wind energy resources and improve the offshore wind energy development plan of all provinces (autonomous regions and municipalities). We will improve the pricing policy for offshore wind energy, improve the service system of offshore wind energy supporting industries, and form the capacity of equipment manufacturing and development and construction covering the whole industrial chain.

\subsubsection{The Development of Hydropower.}

(1) To actively promote the construction of large hydropower bases. On the basis of doing well environmental protection, resettlement and coordinating the electricity market, we should do well in the construction of large hydropower stations along the upper reaches of the Yangtze River and the upper reaches of the Yellow River.

(2) Change ideas to optimize the development of small and medium sized basins. Considering the ecological environment factors, the development and protection of the whole basin and dry tributaries should be coordinated. According to the principle of the priority of the main stream development in the basin and the priority of the protection of the tributaries, the development of the small and medium river basins and the small and medium hydropower is strictly controlled, the necessary habitat of the basin is retained and the ecological health of the basin is maintained.

(3) Accelerate the development of pumped storage. We should speed up the construction of pumped storage power stations in accordance with the requirements of regional nuclear power and new energy resources development, the situation of inter-regional power transmission and the safe and stable operation of power grids. We should implement the construction conditions of the planning site and speed up the construction of a number of pumped storage power stations which are close to the loads, and can promote the new energy resources dissipation. 


\subsubsection{The Development of Nuclear Energy.}

The development process of nuclear power should ensure the safety and efficiency of nuclear power, optimize the distribution of nuclear power production capacity, construct a reasonable supply system of nuclear fuel security, and properly handle radioactive waste.

\subsubsection{The Development of Biomass Energy.}

(1) Accelerate the demonstration and industrialization development of bio gas. In order to promote the development of biological natural gas technology and modernize the construction of natural gas, we should choose the rich farming county with abundant organic waste resources, establish the industrial system in the county, carry out the construction of the demonstration county of biological and natural gas, and promote the progress of biological natural gas technology and the construction of the project.

(2) Actively develop the heat of biomass energy. Combined with the heat demand, the biomass power generation projects have been modified to improve the biomass energy utilization efficiency, and the biomass co generation is actively promoted to the county town and the industrial park.

(3) The steady development of biomass power generation. On the premise of doing a good job of site selection and implementing environmental protection measures, combined with the new urbanization process, the emphasis is on the cities and some counties with resource conditions, and the incineration of municipal solid waste is steadily developed for power generation.

\subsection{Strengthening Chinese International Energy Cooperation.}

It can be foreseen that by 2050, Chinese energy structure is based on fossil fuels, and the dependence of fossil fuels raw materials such as crude oil, natural gas and raw coal is becoming more and more dependent, and the international energy cooperation in China is becoming more and more important. At present, Chinese cooperation with international energy sources has such characteristics as too concentrated import sources, single route of cooperative transportation, and high transportation risk [7]. China can strengthen Chinese international energy cooperation through three aspects.

(1) Cooperate with international oil sources, gas sources and coal sources to ensure the safety of crude oil, natural gas and raw coal supply. China should actively participate in the investment and development of oil source, gas source and coal source, which can not only output the strength and influence of its own country, but also obtain a certain proportion of oil, gas and coal.

(2) To actively carry out bilateral cooperation in energy international. Strengthening international cooperation and increasing the stability and transparency of domestic energy policies and market information can eliminate the suspicion and concern of other countries and promote the stability of the international market. China should take an active part in energy cooperation in East Asia and Northeast Asia, cooperate with Russia and Central Asia, and cooperate with Middle East countries. China should also stabilize its political, economic and diplomatic relations with countries and regions that import fossil fuels such as crude oil.

(3) Implementing the diversification strategy.

A: The import of fossil fuels sources is diversified and the source of fossil fuels sources are dispersed, and the supply of fossil fuels sources from unstable areas in the Middle East and through unstable sectors are avoided.

B: Multiple transport channels and modes of transportation. In order to reduce the serious dependence on the sea transport channel and prevent the interference and destruction of the sea energy transport under the very situation, the strategic layout of Chinese energy transport should be further tilted to the land on the land.

\section{Conclusion}

Based on the background of global energy interconnection, this paper analyzes that the international energy consumption structure will realize the fundamental transformation from the main of fossil fuels, supplemented by clean energy, to the main of clean energy and supplemented by fossil fuels. And the development of clean energy will form a new structure of international energy development, which is based on base type and distributed as a supplement. The development of 
renewable energy bases such as hydro energy, wind energy and solar energy will accelerate in the Arctic, equator, and continents. Secondly, this paper studies that the changes of international energy structure will have great impacts on Chinese energy development, including the impact on Chinese energy supply structure and energy security. Finally, this paper puts forward some strategies and suggestions about Chinese response to the global energy interconnection construction and changes in the international energy structure, including actively developing clean energy including solar energy, wind energy, hydropower, nuclear energy and biomass energy, and strengthening Chinese international energy cooperation.

\section{Acknowledgments}

This work is supported by the Science and Technology Project of State Grid of China (The Impact of Global Energy Internet on the World Political Structure). And the Research Base Program Supported by Beijing Social Science Research Funding (15JDJGA089).

\section{References}

[1]. Fang Zhang. Current Energy Situation and Countermeasures to Solve Energy Problems [J]. Science and technology communication, 2013, 5 (03): 49-50.

[2]. Bo Wang, Cahokia Li. Current Situation and Trend of Global Renewable Energy Development [J]. Chinese price, 2018 (05): 44-47.

[3]. Zeya Liu. Global Energy Interconnection [M]. Chinese Electric Power Press, 2015.

[4]. Haiyang Wang. New Changes in the World Energy Structure and Its Impact on China's Energy Security [J]. Journal of Shanghai University (Social Sciences Edition), 2013, 30(06): 1-11.

[5]. Haiphong Du. Games of Big Powers and Redistribution of Power in the Process of Reshaping the International Energy Structure [D]. East China Normal University, 2016.

[6]. Xiao Goo. Study on the Stability of International Energy Cooperation [D]. Jilin University, 201

[7]. Qingyou Guan, Fan He. China's Energy Security and International Energy Cooperation [J]. World Economy and Politics, 2007(11):45-53+4-5. 